\title{
What is that smell? Hummingbirds avoid foraging on resources with defensive insect compounds
}

\author{
Ashley Y. Kim ${ }^{1,2} \cdot$ David T. Rankin $^{2,3} \cdot$ Erin E. Wilson Rankin ${ }^{2}$
}

Received: 10 May 2021 / Revised: 5 August 2021 / Accepted: 9 August 2021 / Published online: 3 September 2021

(c) The Author(s) 2021

\begin{abstract}
Hummingbirds utilize visual cues to locate flowers, but little is known about the role olfaction plays in nectar foraging despite observations that hummingbirds avoid resources occupied by certain insects. We investigated the behavioral responses of both wild and captive hummingbirds to olfactory cues of hymenopteran floral visitors, including native wood ants (Formica francoeuri), invasive Argentine ants (Linepithema humile), and European honeybees (Apis mellifera). We demonstrate for the first time that hummingbirds use olfaction to make foraging decisions when presented with insect-derived chemical cues under field and aviary conditions. Both wild and captive hummingbirds avoided foraging on feeders with defensive chemicals of $F$. francoeuri and aggregation pheromones of $L$. humile, but showed no response to honeybee cuticular hydrocarbons. Our experiments demonstrate the importance of olfaction in shaping hummingbird foraging decisions.
\end{abstract}

\section{Significance statement}

Recent reviews reveal that avian olfaction is not just limited to vultures and a few taxa. We demonstrate that a very charismatic group, hummingbirds, avoid defensive and aggregatory chemical cues from insects present at nectar resources. Olfactory cues can provide critical information about the presence and potential threat of insect floral visitors. This study raises new questions about the underrated importance of olfaction in avian foraging and specifically, hummingbird foraging.

Keywords Foraging $\cdot$ Context-dependency $\cdot$ Behavioral avoidance $\cdot$ Olfaction

\section{Introduction}

How foraging decisions are made remains a key question in ecology (Sutherland et al. 2013). For nectar-feeding organisms, the presence of a floral visitor may indicate that the nectar reward is currently being exploited (Yokoi and Fujisaki 2011). Thus, hummingbirds should avoid visiting flowers empty of nectar to optimize their foraging efficiency and minimize energy expenditure (Hurly 1996; Tello-Ramos

Communicated by P A. Bednekoff.

Erin E. Wilson Rankin

e.wilson.rankin@gmail.com

1 Department of Entomology and Nematology, University of California, Davis, Davis, CA, USA

2 Department of Entomology, University of California, Riverside, Riverside, CA, USA

3 Department of Evolution, Ecology, and Organismal Biology, University of California, Riverside, Riverside, CA, USA et al. 2019). Hummingbirds utilize their exceptional spatial memory to help identify flowers that they themselves have recently visited (e.g., Hurly 1996; Sandlin 2000; Ornelas and Lara 2015). However, hummingbirds use different sensory modalities when avoiding intra- or interspecific competition for resources.

Incoming floral visitors can use visual, olfactory, or auditory cues to inform their decision to visit a resource (Nordström et al. 2017). Hummingbirds rely primarily on vision and hearing to detect and avoid other avian floral visitors. In hummingbird-hummingbird interactions, additional factors such as behavioral dominance and body size mediate competitive outcomes and resource visitation patterns (Lopez-Segoviano et al. 2018; Marquez-Luna et al. 2018, 2019). However, the drivers of hummingbird-insect interactions at nectar resources are less well-studied. The potential for nectar competition among insects and hummingbirds has been documented (Fig. 1; e.g., Carpenter 1979; Stoaks 2000; Hazlehurst and Karubian 2018). Recent studies have found that hummingbirds avoid feeders with several species 
Fig. 1 Hummingbird visitation to feeders and wildflowers. (A) Costa's hummingbird visiting Cleveland sage. (B) Allen's hummingbird foraging on a flower next to a honey bee. (C) Allen's hummingbird drinking from adjacent port to honey bee on a feeder. (D) Costa's hummingbird drinking from feeder ignoring several honey bees also on a feeder. Photos provided with permission by David Rankin (A, C, and D) and Michael Pazzani (B)

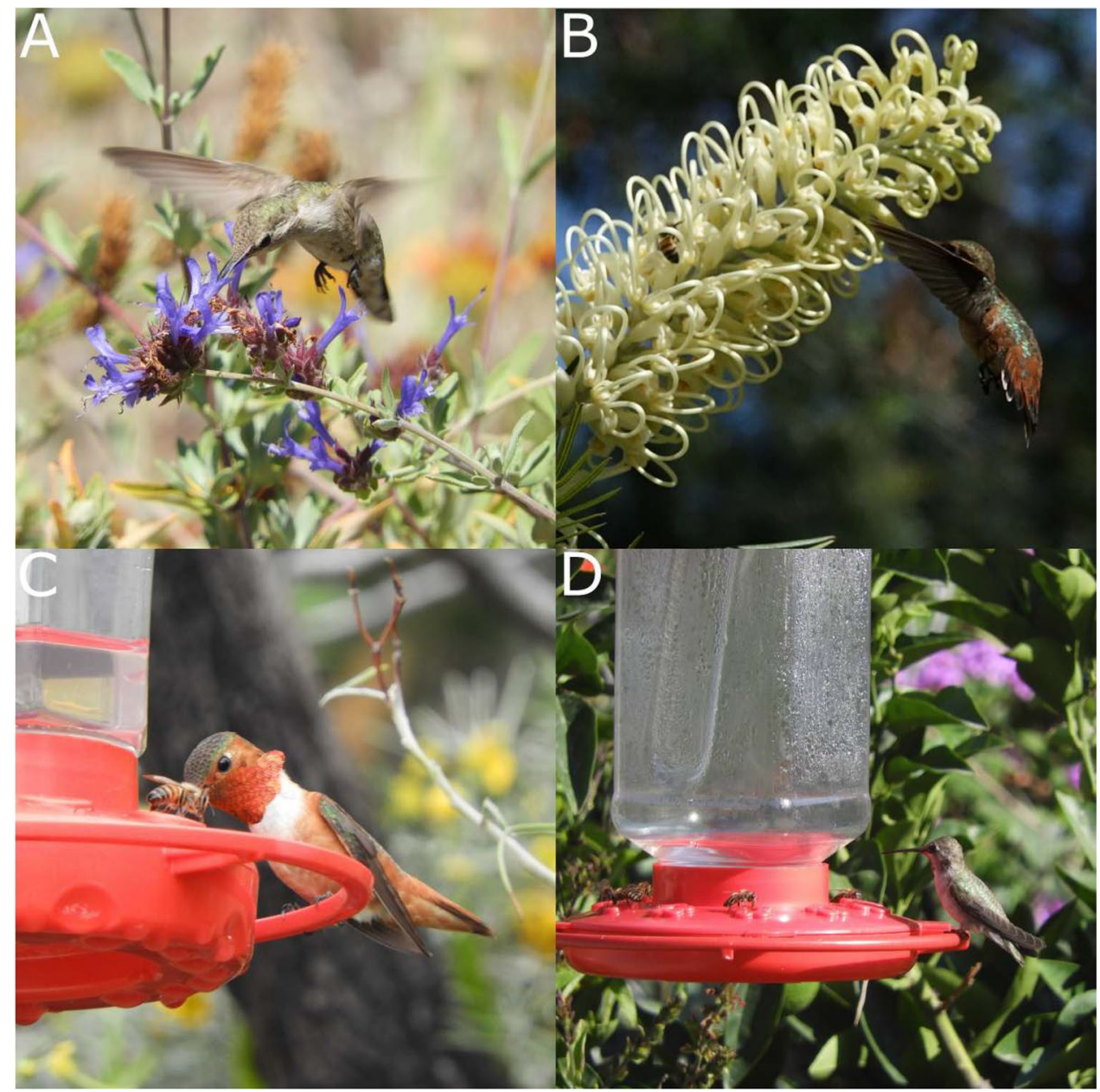

of vespid wasps (Carr and Golinski 2020), and that hummingbirds avoid nectar resources with Argentine ants in them (Rankin et al. 2018). However, no study to date on insect competitors of hummingbirds has identified the underlying mechanisms (e.g., interference, exploitative, or both) of competition.

However, little is known about the cues hummingbirds use to detect and respond to floral arthropods. Bees, wasps, and ants may drain nectar in flowers they visit or aggressively repel hummingbirds from flowers they occupy. Moreover, bees and ants may deposit chemical cues at flowers during foraging and agonistic interactions (Witjes and Eltz 2009; Choe et al. 2012; Touchard et al. 2016). Historically, avian olfaction has been considered relatively unimportant (Balthazart and Taziaux 2009; Avilés and Amo 2018), especially in comparison to mammal or insect olfaction. Moreover, insect- (Wright and Schiestl 2009; Rusch et al. 2016) and mammal-pollinated (Muchhala and Serrano 2015; Wester et al. 2016) plants have strong floral odors, whereas bird-pollinated plants are reported to have little, if any, floral odor (Knudsen et al. 2004). Thus, hummingbirds have been assumed to not use olfaction during foraging (but see Kessler and Baldwin 2007), and comparatively little is known about the hummingbird's ability to smell (Stong 1960; Goldsmith and Goldsmith 1982).

While hummingbirds are not thought to rely on olfaction for floral location (Knudsen et al. 2004), to our knowledge, no study to date has investigated hummingbird olfaction in any context other than associative learning of odor with nectar rewards (e.g., Goldsmith and Goldsmith 1982; Ioale and Papi 1989) or response to floral associated odors (Kessler and Baldwin 2007). The importance of avian olfaction in non-food discovery contexts is gaining recognition (Caro and Balthazart 2010; Apps et al. 2015; Avilés and Amo 2018). Recent studies have revealed the importance of chemosignaling in avian reproduction (Caro et al. 2015), as well as predator avoidance in some passerine (Amo et al. 2008; Roth et al. 2008) and game birds (Mahr and Hoi 2018). Yet, no study to date has investigated hummingbird olfaction in the context of potential insect competitors. We designed a series of experiments to examine hummingbird responses to insect-associated chemical cues that they may encounter at a floral resource: cuticular hydrocarbons (associated with honeybee foraging), formic acid (Formica ant defense 
chemical), and (Z)-9-hexadecenal (Argentine ant aggregation pheromone).

\section{Methods}

We conducted choice tests with free-foraging wild hummingbirds and individual hummingbirds in aviaries. In both situations, hummingbirds were exposed to a series of insect-derived chemicals that they may encounter at flowers at field-realistic levels, such that at least one insect equivalent of the odor was present at the end of each trial (Fig. S1). Specifically, we tested wild and captive hummingbird responses to cuticular hydrocarbons (CHCs) of European honey bees (Apis mellifera); formic acid, a defensive compound produced by Formica ants; and (Z)-9-hexadecenal, which is an aggregation pheromone of Argentine ants (Linepithema humile). Our experimental design excluded visual cues (Fig. S2); thus, all observed behaviors were responses to chemical cues. It was not possible to record data blind because our study involved focal animals in the field.

Cuticular hydrocarbons of European honeybees We removed all legs from honeybees (Apis mellifera) and placed them into $100 \mu \mathrm{L}$ of hexane per bee. After incubating at room temperature for $5 \mathrm{~min}$, the liquid was pipetted from the vial and placed into a new glass vial with a teflon sealed cap until used in choice tests. We used hexane as the control solution. Because hexane dissipates rapidly in the field conditions and previous studies found hexane was no longer detectable by insect floral visitors $20 \mathrm{~min}$ after application (Sidhu and Wilson Rankin 2016), we began trials $20 \mathrm{~min}$ after the solutions were applied. The $100 \mu \mathrm{L}$ represents one bee equivalent; given that CHCs can persist for up to $24 \mathrm{~h}$ (Witjes and Eltz 2009), this meant that 1 bee equivalent would have persisted throughout the entire trial.

Formic acid of Formica francoeuri Formic acid (SigmaAldrich, St. Louis, MO) was diluted in water to $60 \%$ concentration, to represent the concentration of the formic acid sprays of Formica ants (O'Rourke 1950). Water was used as the control solution in all formic acid trials. Observations began immediately after solutions were applied. While formic acid is very volatile, it was still detectable on the filter papers up to $30 \mathrm{~min}$ after application (Fig. S1). The $100 \mu \mathrm{L}$ represents 21-30 ant equivalents of formic acid (O'Rourke 1950; Löfqvist 1977; Morgan 2008); a higher level of ant equivalents was used in this experiment due to the high volatility of formic acid and to ensure that at least 1 ant equivalent was present at the end of the trial.

(Z)-9-hexadecenal pheromone of Linepithema humile ( $Z$ )9-hexadecenal pheromone (Bedoukian Research Inc.,
Danbury, CT) was diluted with ethanol as a solvent to give a concentration of $1 \mathrm{ng} / \mu \mathrm{L}$. Based on Choe et al. (2012), we estimate that this represents 4.3 ant-equivalents. Ethanol was used as the control solution in all (Z)-9-hexadecenal pheromone trials. Observations began immediately after solutions were applied. Previous work by Miner (2018) showed that $46 \%$ of the pheromone was still detectable on the filter paper after $30 \mathrm{~min}$ and that at least 1 ant equivalent was present at the end of the trial.

Behavioral assays (wild, free-foraging birds) To assess hummingbird responses in an unrestricted manner, we presented wild Allen's (Selasphorus sasin sasin), Anna's (Calypte anna), and Costa's (Calypte costae) hummingbirds with two feeders (First Nature, Rogers, AR) hung $1.5 \mathrm{~m}$ off the ground and $0.5 \mathrm{~m}$ apart in Moreno Valley, CA, USA. One feeder was a control, the other the treatment feeder. Each feeder contained $20 \%$ sucrose solution and had filter paper circles (50 mm diameter, GE Life Sciences, Chicago, IL) surrounding 3 of the 8 ports; all remaining ports were blocked. Filter paper circles on the control feeder were treated with $100 \mu \mathrm{L}$ water or the appropriate solvent, and filter paper circles on the treatment feeder were treated with $100 \mu \mathrm{L}$ of the insectderived chemical of interest at field-realistic levels (see electronic supplementary material). Because large numbers of wild hummingbirds were accustomed to visiting the feeders, it was impossible to distinguish the identity of individual hummingbirds. Therefore, because wild hummingbirds often feed every 20-30 min (Wethington et al. 2005; Rankin et al. 2018), trials were $10 \mathrm{~min}$ in duration to limit the chance of repeat visits by the same bird during a trial. All trials with wild birds were conducted between 7:00 am and 9:00 am to maximize bird visitation. For each trial, we noted the ambient temperature and recorded the number and duration of every feeding visit to each feeder. Feeder positions were switched after each trial to avoid any bias in feeder position. We considered a feeding visit to occur when a bird inserted its bill into the feeder and fed for $>1 \mathrm{~s}$. For each chemical, we conducted four trials with wild birds.

To confirm that hummingbirds responded to the odors presented and were not just avoiding novel odors, we tested wild hummingbird responses to ethyl butyrate, a food additive that has been used to test olfactory learning and discrimination in a diversity of animal systems (e.g., Goldsmith and Goldsmith 1982; Angely and Coppola 2010; Cunningham et al. 2016; Lee et al. 2017; Stuhl 2020) including hummingbirds. Using the same setup as described above, wild hummingbirds were presented with ethyl butyrate diluted to a $5 \%(\mathrm{v} / \mathrm{v})$ solution with ethanol as the solvent, a concentration comparable with that of Goldsmith and Goldsmith (1982). Six trials were conducted using the same methods as described above providing wild birds with the choice 
between control feeder (ethanol solvent only) and the 5\% ethyl butyrate feeder.

Behavioral assays (individual birds) To assess the choices of individual birds in a controlled setting, we repeated the choice experiments in aviaries with 11 wild-caught Blackchinned (Archilochus alexandri), Costa's, and Anna's x Costa's hybrid (Calypte anna $x$ costae) hummingbirds following the methods of Rankin et al. (2018). All birds were wildcaught; two birds (the Anna's x Costa's hybrids) were being held in captivity long term, while the recent captives $(N=9)$ were allowed to acclimate to the aviary prior to assays and released after participation. Because birds in the aviaries were captive, experiments were conducted between 7:00 am and 4:00 pm depending on individual bird activity. In each choice experiment, two $10 \mathrm{~mL}$ syringes spaced $16 \mathrm{~cm}$ apart were presented to a hummingbird, one treated with an insect olfactory cue (as above) and one control. Each syringe contained $20 \%$ sucrose solution and had a circular piece of filter paper $50 \mathrm{~mm}$ in diameter surrounding the tip of each syringe. Individual birds were observed for $15 \mathrm{~min}$ (formic acid) to $1 \mathrm{~h}$ (CHCs and (Z)-9-hexadecenal) after application depending on the volatility of the chemical cue being tested to ensure that one-bee or one-ant equivalent of the chemical persisted through the end of the trial. Half-way through each trial, we switched the position of the syringes to avoid any spatial bias (Rankin et al. 2018). Data collection was the same as described above for wild hummingbirds. Each bird participated in four to five trials per chemical tested.

\section{Statistical analyses}

All data were analyzed using linear mixed models with the lmer function from package "Ime4" (Bates et al. 2013) in R v.3.6.2 (R Core Team 2021). Means are reported \pm standard errors. For wild birds, we analyzed feeding visit duration, and number of feeding visits per trial, where chemical treatment, Z-standardized ambient temperature, interaction of treatment and Z-standardized temperature, and trial were fixed effects, and date were random effects. To assess treatment effects, we compared the full model with a model with treatment removed using the anova function. Because aviary trials were repeated observations on the same individuals and analyses revealed no species effect, we followed the same approach; however, we included species and bird identity as random effects. For all experiments, we observed no effects of temperature nor were any effects of trial $(p>0.05)$ detected in post-hoc Tukey tests, indicating individual hummingbirds responded consistently across trials (Table S1). To compare visitation effect sizes across chemical cue types and between wild and aviary birds, we calculated the log response ratio (lnRR) by calculating the natural $\log$ of the visit frequency to chemical cue at a feeder divided by the visit frequency to the control feeder ( $\ln ($ experimental/ control)), following the approach of Holt et al. (2008). We assessed preference or avoidance of a chemical by whether these log ratios with their $95 \%$ CI were greater or less than 0 (Wilson-Rankin 2014). We also calculated the effect size of Pearson $r$ correlation using the package "effectsize" (Ben-Shachar et al. 2020) and categorized the strength of the effect size (e.g., small, moderate, or large) following the recommendations of Gignac and Szodorai (2016).

\section{Results}

Cuticular hydrocarbons of European honeybees Hummingbirds showed no response to honeybee cuticular hydrocarbons by any of our metrics. No hummingbird discriminated between feeders treated with honeybee $\mathrm{CHC}$ extracts and control feeders in terms of visitation frequency (Fig. 2A, B: wild: $X^{2}{ }_{1}=0.295, p=0.86$; aviary: $X^{2}{ }_{2}=2.394, p=0.12$ ) or average visit duration (wild: $X^{2}{ }_{1}=0.24, p=0.62$; aviary: $\left.X^{2}{ }_{1}=0.0071, p=0.93\right)$.

Formic acid of Formica francoeuri Hummingbirds strongly avoided feeders treated with formic acid, which is a defensive compound found in venoms of many Formicine ants (Touchard et al. 2016), including $F$. francoeuri. As this was a very volatile compound and all experiments were conducted outdoors, we limited observations to the first $\sim 15 \mathrm{~min}$ after applying formic acid to filter paper. Hummingbirds consistently visited the control feeder $200 \%$ more often in the wild (Fig. $2 \mathrm{C}: X^{2}{ }_{1}=10.9, p=0.001$ ) and $40 \%$ more often in the aviaries (Fig. 2D: $X^{2}=4.610, p=0.032$ ) than the formic acid-treated feeder. However, individual visits were similar in duration to both feeders for wild hummingbirds (formic acid: $5.0 \pm 0.7 \mathrm{~s}$ vs control: $5.7 \pm 0.5 \mathrm{~s} ; X^{2}{ }_{1}=3.31, p=0.07$ ) and captive hummingbirds (formic acid: $7.2 \pm 1.2 \mathrm{~s}$ vs control: $6.8 \pm 0.9 \mathrm{~s} ; X^{2}{ }_{1}=1.047, p=0.31$ ).

(Z)-9-hexadecenal pheromone of Linepithema humile We further observed that hummingbirds exhibited avoidance of (Z)-9-hexadecenal, an aggregation pheromone found in Argentine ants (Choe et al. 2012, 2014). Hummingbirds consistently visited the control feeder $28 \%$ and $33 \%$ more often than the ant-pheromone treated feeder for wild and captive birds, respectively (Fig. 2E: wild: $X^{2}{ }_{1}=4.98, p=0.026$; Fig. 2F: aviary: $\left.X^{2}{ }_{1}=5.79, p=0.016\right)$. Yet hummingbirds spent similar durations feeding during individual visits to both feeders for both wild ((Z)-9-hexadecenal: $7.7 \pm 0.9 \mathrm{~s}$ vs control: $\left.7.3 \pm 0.8 \mathrm{~s} ; X^{2}{ }_{1}=0.052, p=0.82\right)$ and captive birds ((Z)-9-hexadecenal: $6.2 \pm 0.8 \mathrm{~s}$ vs control: $5.6 \pm 0.5 \mathrm{~s}$; $\left.X^{2}{ }_{1}=0.25, p=0.62\right)$. 
Fig. 2 Insect-derived chemicals alter hummingbird visitation to sugar resources in wild and captive hummingbirds. Top: effect of honey bee cuticular hydrocarbons on feeder visitation rate in (A) wild and (B) aviary. Middle: effect of formic acid on feeder visitation rate in $(\mathrm{C})$ wild and (D) aviary. Bottom: effect of (Z)-9-hexadecenal on feeder visitation rate in (E) wild and (F) aviary. Error bars indicate standard error. $* p<0.05$. $* * p<0.01$. *** $p<0.001$
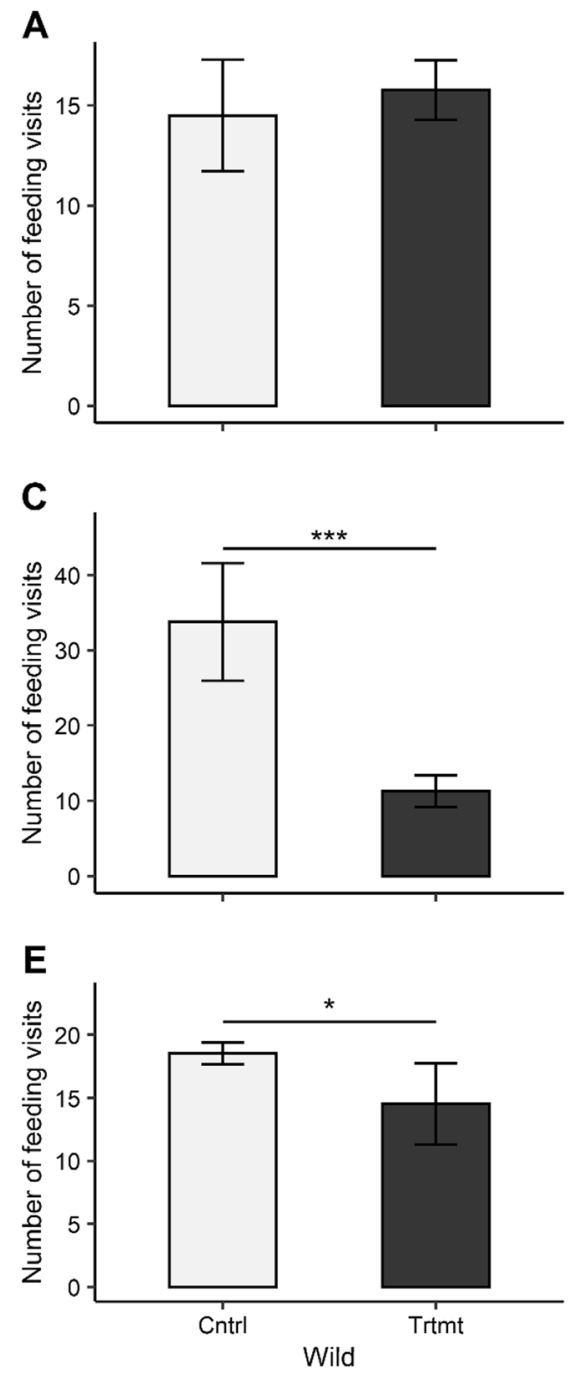
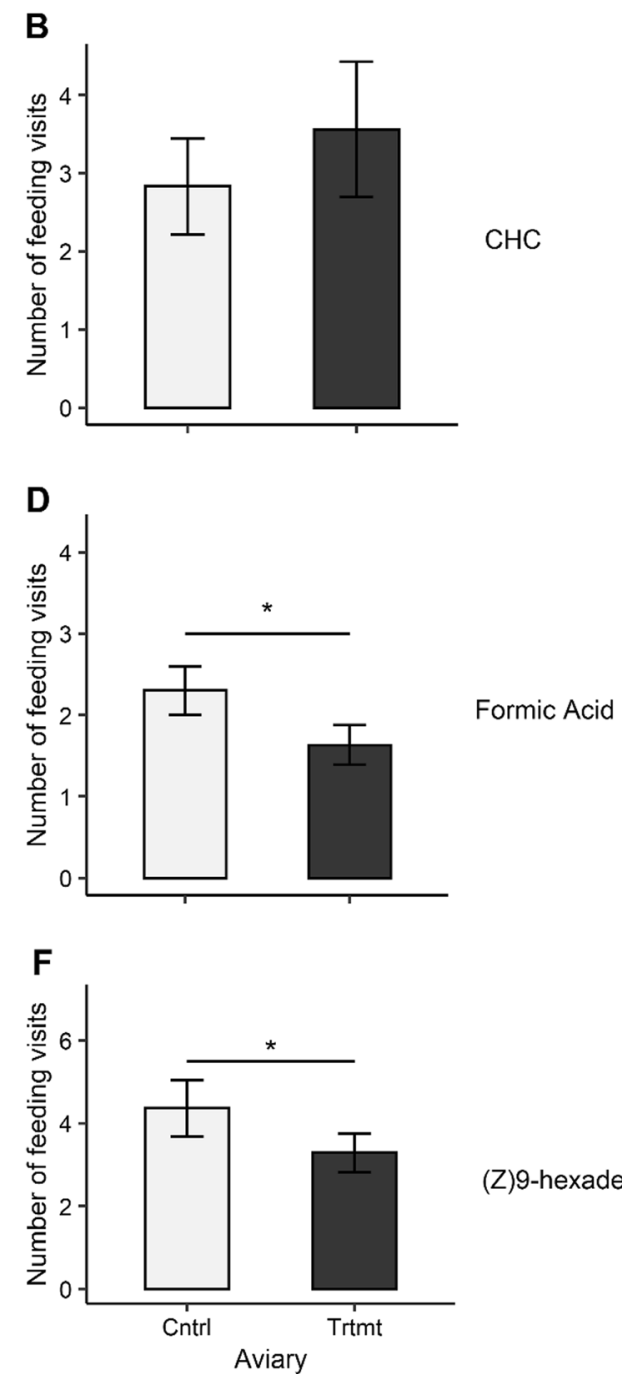

(Z)9-hexadecenal

\section{Comparison of effect sizes across insect-derived chemical cues}

While birds did not respond to ethyl butyrate in any metric analyzed (Table S2), we observed consistent responses to each insect-derived chemical cue across a variety of effect size measures (Table 1). Wild birds appeared to exhibit a stronger avoidance to formic acid than captive birds. While all birds avoided (Z)-9-hexadecenal (Table 1), the strength of this avoidance may have been stronger in wild birds, although log response ratios did not differ. In contrast, the effect sizes between wild and captive birds in response to CHCs did not vary (Table 1).

\section{Discussion}

Known for their visual acuity, hummingbirds in this study exhibited the ability to use olfaction to make foraging decisions, and this is the first study to demonstrate the response of hummingbirds to insect-derived chemicals in a foraging context. Because our experimental design did not provide any visual cues (Fig. S2), the reported behaviors were

Table 1 Comparison of effect sizes across chemical cues for visitation rates of wild and captive birds. Effect size is represented by the mean $\log$ response ratio $(\operatorname{lnRR}) \pm 95 \% \mathrm{CI}$ and strength of association by $r$ (also known as the binomial effect size display). ${ }^{\text {n.d. }}$ The $95 \%$ CI crosses 0 (no effect); ${ }^{\dagger} 95 \% \mathrm{CI}<0$ (avoidance of chemical); ${ }^{\ddagger} 95 \%$ $\mathrm{CI}>0$ (preference for chemical); ${ }^{*}$ indicates moderate effect size and ${ }^{* *}$ large effect size following the recommendations of Gignac and Szodorai (2016)

\begin{tabular}{|c|c|c|c|c|}
\hline & \multicolumn{2}{|l|}{ Wild } & \multicolumn{2}{|l|}{ Aviary } \\
\hline & $\operatorname{lnRR}$ & $r$ & $\ln R R$ & $r$ \\
\hline $\begin{array}{l}\text { Cuticular hydro- } \\
\text { carbons }\end{array}$ & $0.12 \pm 0.26^{\text {n.d }}$ & 0.139 & $0.17 \pm 0.45^{\text {n.d }}$ & 0.12 \\
\hline Formic acid & $-1.41 \pm 0.47^{\dagger}$ & $-0.70^{* *}$ & $-0.36 \pm 0.32^{\dagger}$ & $-0.27^{*}$ \\
\hline $\begin{array}{l}\text { (Z)-9-hexade- } \\
\text { cenal }\end{array}$ & $-0.33 \pm 0.30^{\dagger}$ & $-0.39^{* *}$ & $-0.42 \pm 0.32^{\dagger}$ & $-0.20^{*}$ \\
\hline
\end{tabular}


solely in response to chemical cues. Both wild and aviary hummingbirds avoided foraging on feeders with defensive chemicals of $F$. francoeuri (Fig. 2C, D) and aggregation pheromones of L. humile (Fig. 2E, F). Because of their high responsiveness to visual-based floral cues, little attention has been paid to hummingbirds' ability to smell in foraging (but see Goldsmith and Goldsmith 1982; Ioale and Papi 1989; Kessler and Baldwin 2007) and no study has examined other ecological contexts such as response to floral-visiting insects. This general omission has further been magnified by studies ignoring these original reports, or an erroneous assumption that the lack of floral odor in many hummingbird-pollinated plants indicates a lack of olfaction ability. Through a series of choice tests under field and aviary conditions, we found that hummingbirds distinguished between untreated feeders and those treated with insect defensive compounds or ant aggregation pheromones. Due to the volatility of the insect compounds tested and the subsequent short-lived nature of the cues, hummingbirds may use the presence of these chemicals as an indicator of the presence of ant competitors at a nectar resource.

We observed that the strongest aversion was to formic acid, a defensive compound of Formicine ants presented at field-realistic levels. Floral-visiting Formica species (Wagner and Kay 2002; Galen 2005; Li et al. 2008; Schiestl and Glaser 2012) occur on plants that hummingbirds visit in the area and may interact with hummingbirds at floral resources. Such competition among hummingbirds and nectar-thieving ants is common in a diversity of systems (McDade and Kinsman 1980; Willmer and Corbet 1981; Lach 2005; Stacey 2011). However, there are serious, potentially fatal effects of such exposure if sufficient amounts of formic acid are consumed or enter the bloodstream (Bennett et al. 1996). Our experimental setup, however, prevented the hummingbirds from contacting the formic acid directly or with their tongue and thus were able to assess the birds' response to its odor alone.

In addition to dangerous chemicals, hummingbirds may encounter aggressive insects at flowers. Argentine ants have been documented to harass pollinators (e.g., Hanna et al. 2015), leading to ant avoidance by bees (Cembrowski et al. 2014; Sidhu and Wilson Rankin 2016) and hummingbirds (Stacey 2011; Rankin et al. 2018). Here, we found that hummingbirds visited the control feeder more often as compared to the (Z)-9-hexadecenal pheromone-treated feeder. While not known to be associated with defense (Welzel et al. 2018), (Z)-9-hexadecenal is associated with foraging L. humile ants (Choe et al. 2014), and the number of ants present correlates with the strength of the (Z)-9-hexadecenal pheromone. As Argentine ants are capable of severely depleting floral resources in hummingbird visited flowers (Stacey 2011), avoidance may decrease nectar competition. Moreover, because our experimental setup prevented direct contact with (Z)-9-hexadecenal, it is not surprising that we observed avoidance responses that were less extreme than those observed when gustatory cues of Argentine ants are experienced by hummingbirds (Rankin et al. 2018).

It is important to note that the responses to insect-associated cues documented in this study are not simply the avoidance of a novel stimulus. When presented with this novel but neutral odor (ethyl butyrate) that lacks biological relevance, wild hummingbirds failed to avoid treated feeders (Table S2) although hummingbirds have been shown to distinguish 5\% ethyl butyrate in learning trials (Goldsmith and Goldsmith 1982).

In contrast to defensive chemicals and aggregation pheromones of locally encountered ant species, hummingbirds exhibited no response to cuticular hydrocarbons of a commonly encountered floral-visitor, the European honeybee ( $A$. mellifera). Foraging hummingbirds may have been unable to detect honeybee CHCs or did not use these CHCs as cues. CHCs, which are incidentally deposited by all insects while walking and visiting flowers (Lockey 1988; Witjes et al. 2011) are relatively non-volatile, lasting for several (Eltz 2006) to $24 \mathrm{~h}$ after deposition (Witjes and Eltz 2009). Because many hummingbird-pollinated flowers contain nectar that may be partially or wholly inaccessible to relatively shorter-tongued honeybees, hummingbirds may not view the recent presence of honeybees at a floral resource as a reason to avoid (Fig. 1). In general, bees are also far more visually obvious around flowers compared to ants and will harass hummingbirds in the air prior to landing or accessing a floral resource (Gill et al. 1982); thus, a lack of visual cues may trump chemical cues in the context of hummingbirdhoneybee interactions.

In this study, we observed consistent responses across hummingbird species in both the wild and the aviaries to defensive and pheromonal ant chemicals, although the strength of avoidance was greater for wild birds. This may be in part due to the fact that free-foraging birds in the wild had the option of feeding elsewhere on flowers or other feeders in the local environment, while captive birds were limited just to the two presented feeders. While other studies have found hummingbirds can learn to associate some odors with food rewards and they may avoid extremely strong floral-derived odors, there are only a handful of studies examining hummingbird olfaction and this is the first to explicitly test and document hummingbird response to insect odors alone. Our findings correspond with another recent study examining hummingbird responses to interacting with live Argentine ants (Rankin et al. 2018). Hummingbirds must deal with both exploitative and interference competition from floral visiting arthropods, and using chemical cues may be one mechanism by which they avoid ant competitors. The use of olfactory cues by hummingbirds to make foraging decisions may be more widespread than previously recognized. 
Future studies are needed to investigate the olfactory threshold required to elicit the observed avoidance behavior as well as to examine how learning or habituation influences an individual hummingbird's response to non-floral olfactory cues encountered while foraging. This study provides new insights into how hummingbirds respond to insect chemical cues and the role of olfaction in shaping hummingbird foraging decisions may be more expansive than previously recognized.

Supplementary Information The online version contains supplementary material available at https://doi.org/10.1007/s00265-021-03067-4.

Acknowledgements We gratefully thank C.J. Clark for supervision on experiments, K.J. Loope and J.C. Millar for assistance with chemical extractions, and the anonymous reviewers for their comments on this manuscript.

Author contribution EWR and AYK conceived the study, AYK and DTR conducted aviary research, DTR and EWR conducted wild hummingbird experiments, EWR conducted statistics, and all authors contributed to writing the manuscript.

Funding Funding was provided in part from the National Science Foundation (NSF) Research Experiences for Undergraduates (AYK), NSF-DEB\#1638728 (EWR) and U.S. Department of Agriculture \#CAR-ENT-5091-H (EWR).

Data availability The datasets generated during and/or analyzed during the current study are available in the Dryad repository (https://doi.org/ 10.6086/D1Q378).

Code availability Not applicable.

\section{Declarations}

Ethics approval All applicable national and/or institutional guidelines for the use of animals were followed. This study followed protocols approved by the University of California, Riverside Institutional Animal Care and Use Committee (IACUC protocol \#20160039). All hummingbirds in aviary studies were captured and banded under USFWS Bird Banding permit \#23516 and CA Fish and Wildlife Permit \#SC006598.

Consent to participate Not applicable.

Consent for publication All authors have approved this manuscript submission.

Conflict of interest The authors declare no competing interests.

Open Access This article is licensed under a Creative Commons Attribution 4.0 International License, which permits use, sharing, adaptation, distribution and reproduction in any medium or format, as long as you give appropriate credit to the original author(s) and the source, provide a link to the Creative Commons licence, and indicate if changes were made. The images or other third party material in this article are included in the article's Creative Commons licence, unless indicated otherwise in a credit line to the material. If material is not included in the article's Creative Commons licence and your intended use is not permitted by statutory regulation or exceeds the permitted use, you will need to obtain permission directly from the copyright holder. To view a copy of this licence, visit http://creativecommons.org/licenses/by/4.0/.

\section{References}

Amo L, Galvan I, Tomas G, Sanz JJ (2008) Predator odour recognition and avoidance in a songbird. Funct Ecol 22:289-293

Angely CJ, Coppola DM (2010) How does long-term odor deprivation affect the olfactory capacity of adult mice? Behav Brain Funct 6:26

Apps PJ, Weldon PJ, Kramer M (2015) Chemical signals in terrestrial vertebrates: search for design features. Nat Prod Rep 32:1131-1153

Avilés JM, Amo L (2018) The evolution of olfactory capabilities in wild birds: a comparative study. Evol Biol 45:27-36

Balthazart J, Taziaux M (2009) The underestimated role of olfaction in avian reproduction? Behav Brain Res 200:248-259

Bates D, Maechler M, Bolker B (2013) lme4: linear mixed-effects models using S4 classes. R package version 0.999999-2, http:// CRAN.R-project.org/package $=$ lme4

Ben-Shachar MS, Lüdecke D, Makowski D (2020) Effectsize: estimation of effect size indices and standardized parameters. J Open Source Softw 5:2815

Bennett ATD, Lloyd MH, Cuthill IC (1996) Ant-derived formic acid can be toxic for birds. Chemoecology 7:189-190

Caro SP, Balthazart J (2010) Pheromones in birds: myth or reality? J Comp Physiol A 196:751-766

Caro SP, Balthazart J, Bonadonna F (2015) The perfume of reproduction in birds: chemosignaling in avian social life. Horm Behav 68:25-42

Carpenter FL (1979) Competition between hummingbirds and insects for nectar. Am Zool 19:1105-1114

Carr JM, Golinski JE (2020) Vigilance behaviors of Ruby-throated hummingbirds (Archilochus colubris) reflect elevated risk of competitive interactions with vespine wasps. Wilson J Ornithol 132:295-305

Cembrowski AR, Tan MG, Thomson JD, Frederickson ME (2014) Ants and ant scent reduce bumblebee pollination of artificial flowers. Am Nat 183:133-139

Choe DH, Tsai K, Lopez CM, Campbell K (2014) Pheromoneassisted techniques to improve the efficacy of insecticide sprays against Linepithema humile (Hymenoptera: Formicidae). J Econ Entomol 107:319-325

Choe DH, Villafuerte DB, Tsutsui ND (2012) Trail pheromone of the Argentine ant, Linepithema humile (Mayr) (Hymenoptera: Formicidae). PLoS ONE 7:e45016

Cunningham JP, Carlsson MA, Villa TF, Dekker T, Clarke AR (2016) Do fruit ripening volatiles enable resource specialism in polyphagous fruit flies? J Chem Ecol 42:931-940

Eltz T (2006) Tracing pollinator footprints on natural flowers. J Chem Ecol 32:907-915

Galen C (2005) Catching ants with honey: an experimental test of distraction and satiation as alternative modes of escape from flower-damaging ants. Oecologia 144:80-87

Gignac GE, Szodorai ET (2016) Effect size guidelines for individual differences researchers. Pers Indiv Differ 102:74-78

Gill FB, Mack AL, Ray RT (1982) Competition between hermit hummingbirds Phaethorninae and insects for nectar in a Costa Rican rain forest. Ibis 124:44-49

Goldsmith KM, Goldsmith TH (1982) Sense of smell in the Blackchinned hummingbird. Condor 84:237-238 
Hanna C, Naughton I, Boser C, Alarcón R, Hung K-LJ, Holway DA (2015) Floral visitation by the Argentine ant reduces bee visitation and plant seed set. Ecology 96:222-230

Hazlehurst JA, Karubian JO (2018) Impacts of nectar robbing on the foraging ecology of a territorial hummingbird. Behav Process 149:27-34

Holt AR, Davies ZG, Tyler C, Staddon S (2008) Meta-analysis of the effects of predation on animal prey abundance: evidence from UK vertebrates. PLoS ONE 3:e2400

Hurly TA (1996) Spatial memory in rufous hummingbirds: memory for rewarded and non-rewarded sites. Anim Behav 51:177-183

Ioale P, Papi F (1989) Olfactory-bulb size, odor discrimination and magnetic insensitivity in hummingbirds. Physiol Behav 45:995-999

Kessler D, Baldwin IT (2007) Making sense of nectar scents: the effects of nectar secondary metabolites on floral visitors of Nicotiana attenuata. Plant J 49:840-854

Knudsen JT, Tollsten L, Groth I, Bergström G, Raguso RA (2004) Trends in floral scent chemistry in pollination syndromes: floral scent composition in hummingbird-pollinated taxa. Bot J Linn Soc 146:191-199

Lach L (2005) Interference and exploitation competition of three nectar-thieving invasive ant species. Insect Soc 52:257-262

Lee S, Kim YJ, Jones WD (2017) Central peptidergic modulation of peripheral olfactory responses. BMC Biol 15:e35

Li P, Luo Y, Bernhardt P, Kou Y, Perner H (2008) Pollination of Cypripedium plectrochilum (Orchidaceae) by Lasioglossum spp. (Halictidae): the roles of generalist attractants versus restrictive floral architecture. Plant Biol 10:220-230

Lockey KH (1988) Lipids of the insect cuticle: origin, composition and function. Comp Biochem Physiol B 89:595-645

Löfqvist J (1977) Toxic properties of the chemical defence systems in the competitive ants Formica rufa and $F$. sanguinea. Oikos 28:137-151

Lopez-Segoviano G, Bribiesca R, Arizmendi MD (2018) The role of size and dominance in the feeding behaviour of coexisting hummingbirds. Ibis 160:283-292

Mahr K, Hoi H (2018) Red-legged partridges perceive the scent of predators and alarm scents of an avian heterospecific. Anim Behav 144:109-114

Marquez-Luna U, Lara C, Corcuera P, Valverde PL (2018) Effect of body size and evolutionary distance in the agonistic interactions of hummingbirds (Trochilidae). Rev Mex Biodivers 89:149-162

Marquez-Luna U, Lara C, Corcuera P, Valverde PL (2019) Factors affecting the dominance hierarchy dynamics in a hummingbird assemblage. Curr Zool 65:261-268

McDade LA, Kinsman S (1980) The impact of floral parasitism in two neotropical hummingbird-pollinated plant species. Evolution 34:944-958

Miner MC (2018) Impacts and underlying mechanisms of interference competition between bumble bees and invasive Argentine ants. M.S. thesis, Department of Entomology, University of California, Riverside

Morgan ED (2008) Chemical sorcery for sociality: exocrine secretions of ants (Hymenoptera: Formicidae). Myrmecol News 11:79-90

Muchhala N, Serrano D (2015) The complexity of background clutter affects nectar bat use of flower odor and shape cues. PLoS ONE 10:e 0136657

Nordström K, Dahlbom J, Pragadheesh VS, Ghosh S, Olsson A, Dyakova O, Suresh SK, Olsson SB (2017) In situ modeling of multimodal floral cues attracting wild pollinators across environments. P Natl Acad Sci U S A 114:13218-13223

O'Rourke FJ (1950) Formic acid production among the Formicidae. Ann Entomol Soc Am 43:437-443
Ornelas JF, Lara C (2015) Differential response to colour tasks on resident and migratory hummingbirds: a field test. Ethol Ecol Evol $27: 357-378$

R Core Team (2021) R: a language and environment for statistical computing. http://www.R-project.org

Rankin DT, Clark CJ, Wilson Rankin EE (2018) Hummingbirds use taste and touch to discriminate against nectar resources that contain Argentine ants. Behav Ecol Sociobiol 72:44

Roth TC, Cox JG, Lima SL (2008) Can foraging birds assess predation risk by scent? Anim Behav 76:2021-2027

Rusch C, Broadhead GT, Raguso RA, Riffell JA (2016) Olfaction in context-sources of nuance in plant-pollinator communication. Curr Opin Insect Sci 15:53-60

Sandlin EA (2000) Foraging information affects the nature of competitive interactions. Oikos 91:18-28

Schiestl FP, Glaser F (2012) Specific ant-pollination in an alpine orchid and the role of floral scent in attracting pollinating ants. Alpine Bot 122:1-9

Sidhu CS, Wilson Rankin EE (2016) Honey bees avoiding ant harassment at flowers using scent cues. Environ Entomol 45:420-426

Stacey LM (2011) The impacts and spread of the Argentine ant (Linepithema humile, Mayr) invasion in coastal sclerophyllous forests of Chile. Ph.D. thesis, School of Forest Resources, University of Washington

Stoaks RD (2000) Foraging interactions at a hummingbird feeder : conflicts of the Anna hummingbird (Aves: Trochilidae) and the prairie yellowjacket (Hymenoptera: Vespidae). Sociobiology 35:49-62

Stong CL (1960) Does a hummingbird find its way to nectar through its sense of smell. Sci Am 202:157-166

Stuhl CJ (2020) The development of an attract-and-kill bait for controlling the small hive beetle (Coleoptera: Nitidulidae). Apidologie $51: 428-435$

Sutherland WJ, Freckleton RP, Godfray HCJ et al (2013) Identification of 100 fundamental ecological questions. J Ecol 101:58-67

Tello-Ramos MC, Hurly AT, Healy SD (2019) From a sequential pattern, temporal adjustments emerge in hummingbird traplining. Integr Zool 14:182-192

Touchard A, Aili SR, Fox EGP, Escoubas P, Orivel J, Nicholson GM, Dejean A (2016) The biochemical toxin arsenal from ant venoms. Toxins 8:30

Wagner D, Kay A (2002) Do extrafloral nectaries distract ants from visiting flowers? An experimental test of an overlooked hypothesis. Evol Ecol Res 4:293-305

Welzel KF, Lee SH, Dossey AT, Chauhan KR, Choe DH (2018) Verification of Argentine ant defensive compounds and their behavioral effects on heterospecific competitors and conspecific nestmates. Sci Rep 8:1477

Wester P, Filla M, Lunau K (2016) Floral scent and flower visitors of three green-flowered Costa Rican and Panamanian Blakea species (Melastomataceae) indicate birds rather than rodents as pollinators. Plant Ecol Evol 149:319-328

Wethington SM, West GC, Carlson BA (2005) Hummingbird conservation: discovering diversity patterns in southwest U.S.A. In: Gottfried GJ, Gebow BS, Eskew LG, Edminster CB (eds) Connecting mountain islands and desert seas: biodiversity and management of the Madrean Archipelago II. USDA Forest Service, Fort Collins, pp 162-168

Willmer PG, Corbet SA (1981) Temporal and microclimatic partitioning of the floral resources of Justicia-aurea amongst a concourse of pollen vectors and nectar robbers. Oecologia 51:67-78

Wilson-Rankin EE (2014) Social context influences cue-mediated recruitment in an invasive social wasp. Behav Ecol Sociobiol 68:1151-1161

Witjes S, Eltz T (2009) Hydrocarbon footprints as a record of bumblebee flower visitation. J Chem Ecol 35:1320-1325 
Witjes S, Witsch K, Eltz T (2011) Reconstructing the pollinator community and predicting seed set from hydrocarbon footprints on flowers. Oecologia 166:161-174

Wright GA, Schiestl FP (2009) The evolution of floral scent: the influence of olfactory learning by insect pollinators on the honest signalling of floral rewards. Funct Ecol 23:841-851
Yokoi T, Fujisaki K (2011) To forage or not: responses of bees to the presence of other bees on flowers. Ann Entomol Soc Am 104:353-357

Publisher's note Springer Nature remains neutral with regard to jurisdictional claims in published maps and institutional affiliations. 